\title{
Deformation of the $S$. aureus Cell Envelope due to Surface Adhesion
}

\author{
Jiahua $\mathrm{Gu}^{1}$, Tsengming $\mathrm{Chou}^{2}$, and Matthew Libera ${ }^{1}$ \\ 1. Dept. of Chemical Engr. \& Materials Science, Stevens Institute of Technology, Hoboken, NJ USA \\ ${ }^{2 .}$ Laboratory of Multiscale Imaging, Stevens Institute of Technology, Hoboken, NJ USA
}

Bacterial biofilms are three-dimensional communities of bacteria. They have structures over multiple length scales and can be highly resistant to antimicrobials [1]. The adhesion of individual bacteria to a surface is the first step in biofilm formation, and understanding this early-stage development might provide information that can be used ultimately to control or prevent biofilm formation. Following standard EM sample-preparation protocols [2], we can fix, stain, and embed early-stage biofilms while maintaining them close to their native state on surfaces that have different adhesion properties. This experimental approach enables us to study their structures using scanning electron microscopy.

Staphylococcus aureus (S. aureus; ATCC-12600) was cultured in a polystyrene (PS) culture dish where half of the dish was coated with $\sim 50 \mathrm{~nm}$ of evaporated gold ( $\mathrm{Au}$ ). The coated surface was further treated with Triethylene glycol mono-11-mercaptoundecyl ether $\left(\mathrm{EG}_{3}\right.$, hydrophilic portion) or 1-Dodecanethiol $\left(\mathrm{CH}_{3}\right.$, hydrophobic portion) thiol. Four different mixed solutions $\left[\mathrm{v} / \mathrm{v} \mathrm{CH} \mathrm{CH}_{3} / \mathrm{EG}_{3}: 0 / 100\left(0 \% \mathrm{CH}_{3}\right) ; 10 / 90\right.$ $\left(10 \% \mathrm{CH}_{3}\right) ; 30 / 70\left(30 \% \mathrm{CH}_{3}\right)$; and $\left.100 / 0\left(100 \% \mathrm{CH}_{3}\right)\right]$ were used to modify surfaces. Five such samples, including an untreated $\mathrm{Au}$ control, were then exposed to identical bacterial inoculation $\left(1 \times 10^{8}\right.$ $\mathrm{CFU} / \mathrm{ml}$ ), 24-hour culture (in tryptic soy broth, refreshed once after $18 \mathrm{hr}$ ), and specimen-preparation processes. Blocks were cut with a small saw and then trimmed, sectioned, and faced using glass knives in a Leica Ultracut S microtome. A Zeiss Auriga 40 FIB-SEM was used to slice and image the samples. For thin sections, a STEM detector in the Auriga was used for ADF imaging at $15 \mathrm{keV}$. For faced bulk samples, the energy-selective-backscattering detector (EsB) was used for serial-sectioned imaging at 1.5 $\mathrm{keV}$. An Atlas 3D (Fibics, Inc.) was used to control the FIB-SEM while collecting the FIB tomography data. A typical dataset contained as many as 1000 images with a $10 \mathrm{~nm}$ to $20 \mathrm{~nm}$ slice thickness. Images were processed and analysed using the Avizo Fire program (FEI Software).

Fig. 1 shows a 3D volume of the biofilm cultured on an unmodified Au surface. If we concentrate on a single bacterium that contacts the surface, we can walk through the serial-sectioned images and observe the morphology (Fig. 2). These images show that bacterial cell envelope is deformed as a consequence of contacting the surface. The adhesion-induced contact area can be measured using the FIB tomography data, and we performed contact-area measurements on all five surfaces. The results are summarized in Table 1. The average contacting area on $0 \% \mathrm{CH}_{3}$ is effectively zero due to the fact that the biofilm contacts this hydrophilic surface very infrequently and presumably at defects in the thiol film. With increasing hydrophobicity, the contact area increases. The average contact area is highest on the unmodified Au surface, suggesting that other forces beyond hydrophobicity control adhesion.

Since the FIB tomography uses EsB imaging on bulk samples, electron delocalization ultimately controls the lateral spatial resolution. Hence, the bright contrast associated with the $\mathrm{OsO}_{4}$-stained cell envelope is convoluted with the bright contrast associated with the gold thin-film substrate within the bacteria-substrate contact area. The fact that ADF-STEM imaging (Fig. 3) of a thin section resolves three layers of structure within the cell envelope, where both the inner and outer have bright contrast, 
suggests that the adhesion-induced envelope deformation involves the outer proteins, the bacterial wall itself, as well as the inner lipid-rich membrane [3].

\section{References:}

[1] Jiahua Gu, Matthew Libera, Tsengming Chou, Microscopy and Microanalysis, Volume 22, Issue S3 (Proceedings of Microscopy \& Microanalysis 2016), July 2016, pp. 172-173

[2] John J. Bozzola, Ch.1 in "Methods in Molecular Biology", vol. 369, ed. J. Kuo, Humana Press, Totowa, NJ, p.1-18

[3] Harapanahalli AK, Younes JA, Allan E, van der Mei HC, Busscher HJ. Chemical Signals and Mechanosensing in Bacterial Responses to Their Environment. PLoS Pathog. 2015;11.

[4] This work has been supported by the United States National Science Foundation (grant \#DMR1608406) and by the Army Research Office (grant \#W911NF-12-1-0331) and uses microscopy resources supported by the National Science Foundation (grants \#DMR-1428296 and DMR-0922522) and the Stevens Institute of Technology.

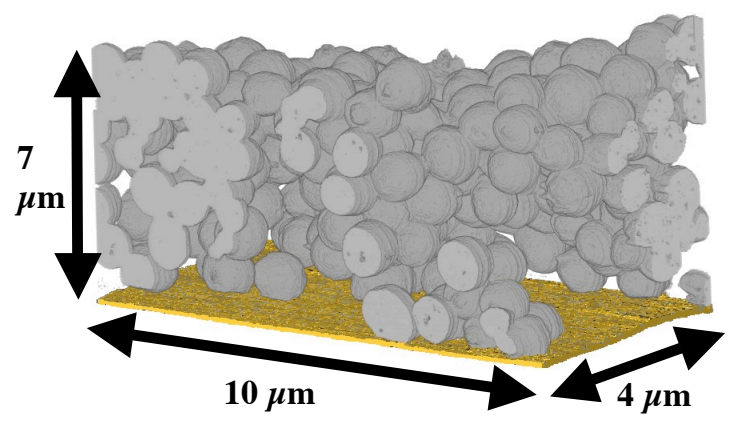

Fig. 1 - 3D image reconstruction of an $S$. aureus biofilm grown on Au. The voxel size is $10 \mathrm{~nm} \times 10 \mathrm{~nm} \times 20 \mathrm{~nm}$.

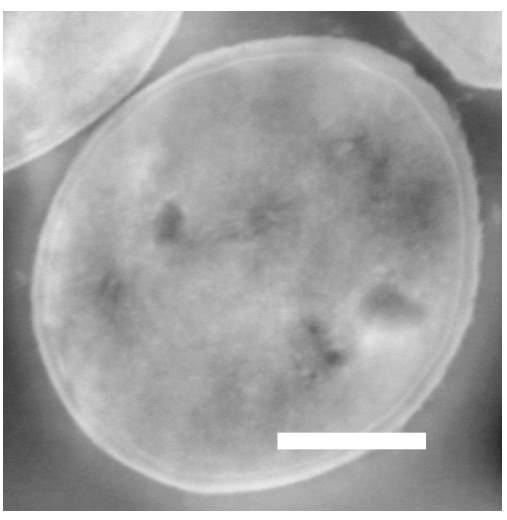

Fig. 3 - ADF-STEM (15 keV) image of a thin sectioned bacterium. The scale marker is $300 \mathrm{~nm}$.
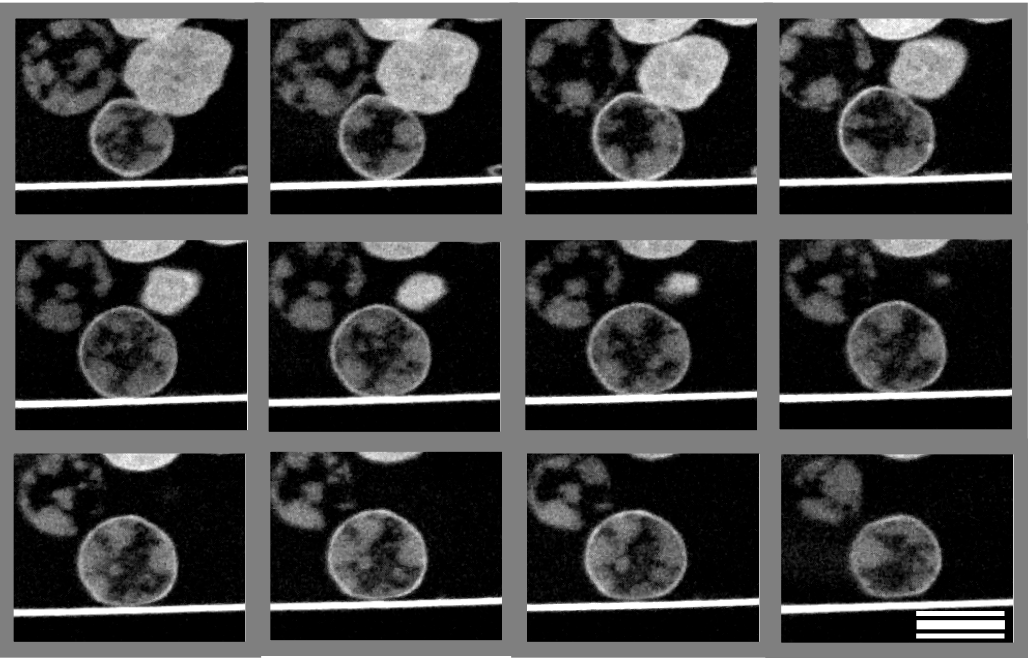

Fig. 2 - Serial-sectioned images of a bacterium adhered to an unmodified Au surface. The slices thickness is $20 \mathrm{~nm}$ and the scale marker is $1 \mu \mathrm{m}$.

\begin{tabular}{|l|l|l|l|l|l|}
\hline & $\begin{array}{l}\mathbf{0 \%} \\
\mathbf{C H}_{3}\end{array}$ & $\begin{array}{l}\mathbf{1 0 \%} \\
\mathbf{C H}_{\mathbf{3}}\end{array}$ & $\begin{array}{l}\mathbf{3 0 \%} \\
\mathbf{C H}_{3}\end{array}$ & $\begin{array}{l}\mathbf{1 0 0 \%} \\
\mathbf{C H}_{3}\end{array}$ & $\mathbf{A u}$ \\
\hline $\begin{array}{l}\text { Contact Area } \\
\left(10^{4} \mathrm{~nm}^{2}\right)\end{array}$ & $\sim 0$ & $6.2 \pm 1.7$ & $8.5 \pm 2.6$ & $10.1 \pm 1.8$ & $20.3 \pm 4.6$ \\
\hline
\end{tabular}

Table 1 - The contact area between an individual bacterium and its substrate depends on the substrate surface properties. 